\title{
Russian attitudes towards humour and laughter
}

\author{
Alyona Ivanova \\ Pirogov Russian National Research Medical University \& Mental Health Research Centre, Moscow, \\ Russia \\ ivalenka13@gmail.com
}

\section{Ekaterina Stefanenko}

Mental Health Research Centre, Moscow, Russia

ekat.stefanenko@gmail.com

\section{Sergey Enikolopov}

Mental Health Research Centre, Moscow, Russia

enikolopov@mail.ru

\begin{abstract}
Different phenomena related to humour and laughter, such as humour styles, gelotophobia, gelotophilia and katagelasticism, were investigated in a series of psychological studies in Russia. As far as the samples were rather heterogeneous in regard with age, gender, region of Russia, and included besides big cities also small towns and villages, the data allows to discuss not only psychological, but also a certain cultural perspective. It is concluded that selfdefeating humour style plays an important role in the structure of Russian cultural attitude towards humour and laughter. The most adaptive affiliative humour style is highly connected with self-defeating and aggressive styles. Similar pattern was shown for humour and laughter perception: a fear of being laughed at paradoxically provokes active involvement into exchange of jokes. A comparison between the two Russian capitals and regional sample revealed more similarities of Moscow and Saint Petersburg with western data than with the regional Russian sample which is supposed to reflect more of traditional national character.
\end{abstract}

Keywords: humour, laughter, humour styles, gelotophobia, Russian humour and laughter.

\section{Background}

Humour and laughter are fairly regarded as a specific human ability. Many studies are dedicated to understanding of humour and laughter nature and the mechanisms of their positive impact to our life. On the other hand, a number of authors highlight the negative side of the phenomena. Humour and laughter may have aggressive character, violate boundaries and 
evoke discomfort and offence. Thus some people are afraid of humour and laughter or have an anxiety of being laughed at. That is why modern scholars strive for differential analysis of humour and laughter motives and opposite patterns of reaction to them (Martin 2007; Ruch 2009; Ruch \& Proyer 2009).

A series of empirical studies on humour styles, fear of being laughed at and related phenomena was conducted in Russia during past five years (Ivanova et al. 2012, 2013, 2014, 2016a, 2016b; Stefanenko et al. 2011, 2013, 2014). As far as the samples were rather heterogeneous in regard to age, gender, region of Russia, and included big cities as well as small towns and villages, the united data allow to discuss not only psychological, but also a certain cultural perspective which became the objective of this article.

For the purposes of this study humour and laughter are taken together as closely related features of the holistic phenomenon, although it is known that they are often unrelated in everyday life (Chafe 2007). Two aspects of humour and laughter were analysed: motivational (from the side of a joker) and perceptional (from the side of the person who perceives this humour and/or laughter). Both of the aspects may be connected with good or bad-natured humour and laughter. Thus a joker may have friendly or aggressive motives for using humour which is described by prevailing humour styles. A person who perceives humour may feel as being the target of the joke or not, and may be delighted or not by this humour and laughter. This perception is independent of the joker's intention to a certain extent. Thus a friendly laughter may be perceived as threatening or vice versa.

The distribution of different humour styles in Russia was analysed in regard with positive/negative intentions of a joker, whereas fear or joy of being laughed at, and joy of laughing at others (gelotophobia, gelotophilia and katagelasticism) were taken as different patterns of attitudes towards laughter.

Understanding of humour complexness led to an idea of distinguishing styles different in regard with their adaptiveness or destructive character (Kirsh \& Kuiper 2003; Martin et al. 2003; Martin 2007). Martin et al. (2003) offered a classification of humour styles based on humour target (self or others) and its good/bad nature. They described affiliative, selfenhancing, aggressive and self-defeating humour styles and elaborated the Humour Styles Questionnaire to measure them as variables of individual differences.

Affiliative humour style is friendly, tolerant, it is aimed at amusing other people and the speaker, to create good atmosphere, to establish emotional contact and support relationships. Self-enhancing humour style reflects humorous outlook on life, an ability to find humour in ambiguities and incongruities of everyday routine. It helps to cope with unpleasant and stressful events. Both affiliative and self-enhancing styles correlate with the variables connected with psychological health such as optimism, self-esteem, positive emotions, relationship and life satisfaction etc., and are negatively related to anxiety and depression (Martin et al. 2003; Martin 2007; Yip \& Martin 2006).

Aggressive humour style is using humour for the purpose of criticising and manipulating people, it may often be offencive. Finally, self-defeating humour style is a tendency to make oneself a target of others' laughter, to amuse others at one's own expense in an excessively self-disparaging way. These humour styles correlate with neuroticism, hostility, aggression, or depression relatively, are negatively related with relationship satisfaction (Martin et al. 2003; Martin 2007; Yip \& Martin 2006; Greengross 2008).

In parallel with different kinds of humour, from the point of view of a joker's intention, humour scholars began to study general attitude towards laughter. Titze $(1996,2009)$ described a special form of social anxiety-gelotophobia or a fear of being laughed at. People with pronounced gelotophobia are characterised by conviction of being ridiculous, inability to appreciate laughter and smiles as joyful social experience, inability to distinguish friendly teasing and aggressive ridicule, perception of all humour as aggressive, high expression of 
shame and anxiety, inability to use humour as coping, controlling body movements (Pinocchio syndrome) (Platt 2008; Ruch 2009; Ruch et al. 2009; Ruch \& Proyer 2008a). Unlike for the majority of people, for people with gelotophobia the impact of humour and laughter to their health, personality and communication becomes mostly negative.

In a multi-national study by Proyer et al. (2009) gelotophobia was studied in 73 countries, totalling 42 languages. The results confirmed the fear of being laughed at to be a universal phenomenon, spread all over the world. Its variability was connected more with cultural differences than language. The profile of the answers was higher in eastern countries than in western.

Ruch and Proyer (2009) suggested that being laughed at is not always unpleasant for a person. Some people like to be a target of jokes and they may even provoke others to laugh at them. The joy of being laughed at was called gelotophilia. Ruch and Proyer suppose it to be a variable which is relatively independent to gelotophobia. Besides fear and joy of being laughed at, the authors distinguished a group of people who prefer to laugh at others which was called katagelasticism. These people take any chance to laugh at others without any concern of possible offenciveness of their actions, and believe that their targets just lack the sense of humour if they are sensitive to the jokes. Ruch and Proyer elaborated a measure to study gelotophobia - the GELOPH (Ruch \& Proyer 2008b) which was later extended to the PhoPhiKat with the additional scales of gelotophilia and katagelasticism (Ruch \& Proyer 2009).

Just as individual sense of humour reflects personality, national sense of humour reflects specific cultural features. That is why the series of psychological studies on humour styles, gelotophobia, gelotophilia and katagelasticism gave the opportunity to analyse specifics of Russian attitudes toward humour and laughter. Moreover, empirical studies in Russia, unlike in the European countries, give a possibility to gather very heterogeneous samples, thus getting not only cultural, but also information about regional variation of humour styles. The large territory of the country with the big gap between cities and small towns and villages, variation in their lifestyle, may make the differences between the residents more contrast than in smaller countries. In this study an attempt is made to analyse besides Russian cultural specifics also differences inside the country through the humour and laughter phenomena.

\section{Method}

In the series of empirical studies the measures of humour styles and attitude towards humour and laughter along with a battery of additional methods were administered totally to more than 1,000 participants, residents of different regions of Russia (Ivanova et al. 2012, 2013, 2014, 2016a, 2016b; Stefanenko et al. 2011, 2013).

The Humour Styles Questionnaire (HSQ) (Martin et al. 2003; Martin 2007) consists of 32 items assessed on a seven-point Likert scale. The items describe different situations of using humour and form four scales: affiliative, self-enhancing, aggressive and self-defeating humour styles. A Russian adaptation was proposed by Ivanova et al. (2013).

The GELOPH $\langle 15>$ was elaborated by Ruch \& Proyer (2008b) as a measure of gelotophobia. It includes 15 items assessed on a four-point Likert scale. A Russian adaptation was proposed by Stefanenko et al. (2011), see also in Ivanova et al. (2012).

The scale was later fully included into the PhoPhiKat along with the scales of gelotophilia and katagelasticism (Ruch \& Proyer 2009). The questionnaire has full (45 items) and short versions (30 items). The final version of its Russian adaptation consists also of 30 items (Ivanova et al. 2016b). 
A number of additional standard scales were used in the studies in order to validate the questionnaires and/or to study related variables: the Buss-Perry Aggression Questionnaire, Russian adaptation of Enikolopov \& Tsybulsky (2007), the Guilt and Shame Proneness Scale, Russian version of Makogon \& Enikolopov (2014), the Liebowitz Social Anxiety Scale, and the Fear of Negative Evaluation Scale adapted by Grigorieva \& Enikolopov (2016), the Coping Humour Scale adapted by Artem'eva (2011).

\section{Results}

Detailed results of each of the study may be found in the works referred to relatively. For the purposes of this study just an overview is made in order to make more general conclusions.

\subsection{Humour styles in Russia}

In general, expression of the humour styles in Russia repeats the original Canadian pattern: in terms of mean scores affiliative humour style is the most spread, followed by self-enhancing, aggressive, and the less expressed self-defeating humour style. Nonetheless, in the Russian sample mean scores on affiliative and self-enhancing humour styles were lower, and aggressive and self-defeating humour styles were higher than in the original Canadian sample (see Table 1 - the Canadian data is given in brackets). The samples were not compared straightly and were close, but not equal, in regard with age and gender, so this is a small observation rather than a strict result, but it's still of certain interest along with the following results.

Table 1. Russian norms on the humour styles (students N=604) (Ivanova et al. 2014)

\begin{tabular}{|l|l|l|l|l|l|l|}
\hline & \multicolumn{3}{l}{ Total } & \multicolumn{2}{l|}{ Men } & \multicolumn{2}{l|}{ Women } \\
\cline { 2 - 7 } & $\mathrm{M}$ & $\mathrm{SD}$ & $\mathrm{M}$ & $\mathrm{SD}$ & $\mathrm{M}$ & $\mathrm{SD}$ \\
\hline Affiliative & $\begin{array}{l}4.5 \\
(5.8)\end{array}$ & $\begin{array}{l}1.01 \\
(0.90)\end{array}$ & $\begin{array}{l}4.7 \\
(5.9)\end{array}$ & $\begin{array}{l}1.02 \\
(0.85)\end{array}$ & $\begin{array}{l}4.4 \\
(5.8)\end{array}$ & $\begin{array}{l}1.00 \\
(0.90)\end{array}$ \\
\hline Self-enhancing & $\begin{array}{l}4.3 \\
(4.7)\end{array}$ & $\begin{array}{l}1.03 \\
(1.04)\end{array}$ & $\begin{array}{l}4.4 \\
(4.7)\end{array}$ & $\begin{array}{l}1.12 \\
(1.00)\end{array}$ & $\begin{array}{l}4.3 \\
(4.6)\end{array}$ & $\begin{array}{l}0.99 \\
(1.06)\end{array}$ \\
\hline Aggressive & $\begin{array}{l}3.7 \\
(3.6)\end{array}$ & $\begin{array}{l}1.00 \\
(1.10)\end{array}$ & $\begin{array}{l}4.2 \\
(4.0)\end{array}$ & $\begin{array}{l}1.15 \\
(1.07)\end{array}$ & $\begin{array}{l}3.6 \\
(3.3)\end{array}$ & $\begin{array}{l}0.89 \\
(1.00)\end{array}$ \\
\hline Self-defeating & $\begin{array}{l}3.4 \\
(2.3)\end{array}$ & $\begin{array}{l}1.13 \\
(1.15)\end{array}$ & $\begin{array}{l}3.5 \\
(3.5)\end{array}$ & $\begin{array}{l}1.22 \\
(1.16)\end{array}$ & $\begin{array}{l}3.4 \\
(3.1)\end{array}$ & $\begin{array}{l}1.09 \\
(1.12)\end{array}$ \\
\hline
\end{tabular}

Gender differences were found in the Russian sample. Not surprisingly, men had higher aggressive humour style than women both in the Moscow $(\mathrm{Mm}=4.21 \mathrm{Mf}=3.65, \mathrm{t}=3.76$ $\mathrm{p}=0.000)$ and regional $(\mathrm{Mm}=4.04 \mathrm{Mf}=3.56, \mathrm{t}=3.60 \mathrm{p}=0.001)$ samples. In the Moscow sample, men also had higher affiliative $(\mathrm{Mm}=4.84 \mathrm{Mf}=4.45, \mathrm{t}=2.89 \mathrm{p}=0.004)$, whereas in the regional Russian sample they expressed higher self-enhancing humour $(\mathrm{Mm}=4.49 \mathrm{Mf}=4.23, \mathrm{t}=1.99$ $\mathrm{p}=0.05$ ) in comparison to women.

The self-defeating humour style has some interesting characteristics: unlike in the Canadian data and opposed also to the very logic of the classification it has a high correlation with affiliative humour (especially in young men) and self-enhancing humour style. Moreover, 
self-enhancing humour style was closer connected with the aggressive humour in young Russian women compared to the Canadian sample. In Table 2 the intercorrelations between the four humour styles are presented as found in students from Moscow $(\mathrm{N}=217)$ and regional sample $(\mathrm{N}=387)$ in comparison with the Canadian sample in which students also prevailed. The upper triangle - for men, the lower-for women.

Table 2. Intercorrelation between the humour styles (Ivanova et al. 2014)

\begin{tabular}{|c|c|c|c|c|c|}
\hline \multicolumn{2}{|l|}{ Women/Men } & \multirow{2}{*}{$\begin{array}{l}\text { Affiliative } \\
- \\
\end{array}$} & \multirow{2}{*}{$\begin{array}{l}\text { Self-enhancing } \\
0.45^{* * *}\end{array}$} & \multirow{2}{*}{$\begin{array}{l}\text { Aggressive } \\
0.47 * * *\end{array}$} & \multirow{2}{*}{$\begin{array}{l}\text { Self-defeating } \\
0.41 * * *\end{array}$} \\
\hline Affiliative & Moscow & & & & \\
\hline & Regions & - & $0.52 * * *$ & $0.34 * *$ & $0.45 * * *$ \\
\hline & Canada & - & $0.33 * * *$ & $0.28 * *$ & 0.04 \\
\hline \multirow[t]{3}{*}{ Self-enhancing } & Moscow & $0.21 *$ & - & -0.04 & 0.13 \\
\hline & Regions & $0.40 * * *$ & - & 0.15 & $0.52 * * *$ \\
\hline & Canada & $0.36^{* * *}$ & - & $0.11 *$ & $0.12 * *$ \\
\hline \multirow[t]{3}{*}{ Aggressive } & Moscow & $0.21 *$ & -0.01 & - & $0.22 *$ \\
\hline & Regions & $0.22 * * *$ & $0.13^{*}$ & - & $0.28 *$ \\
\hline & Canada & $0.22 * * *$ & -0.01 & - & $0.22 * * *$ \\
\hline \multirow[t]{3}{*}{ Self-defeating } & Moscow & $0.26^{* *}$ & 0.10 & $0.26^{* *}$ & - \\
\hline & Regions & $0.37 * * *$ & $0.24 * * *$ & $0.30 * * *$ & - \\
\hline & Canada & 0.06 & 0.04 & $0.23 * * *$ & - \\
\hline
\end{tabular}

The most evident difference between the Moscow and regional samples was that self-defeating and self-enhancing humour styles highly correlated in the later, especially among men, whereas in the Moscow sample they were not related at all. Men from Moscow were more characterised by affiliative humour style than the regional males $(\mathrm{Mm}=4.84 \mathrm{Mr}=4.50, \mathrm{t}=2.03 \mathrm{p}=0.05)$. Women from Moscow, in comparison with the females from regions, had lower correlation between affiliative and self-enhancing humour styles.

Thus, the in Russian sample, in comparison with the Canadian, demonstrates lower expressions of "positive" and higher expressions of "negative" humour styles, as well as stable significant correlations between the "positive" and "negative" styles. Gender differences were found along with the differences between the capital and Russian regions.

\subsection{Gelotophobia, gelotophilia and katagelasticism in Russia}

Ruch and Proyer proposed to interpret gelotophobia using a cut-off value of 2.5 which was strongly confirmed in empirical studies on general population and clinically diagnosed gelotophobes (Ruch 2009). Distribution of gelotophobia in Russian data gave a very close cutoff score (Stefanenko et al. 2011; Ivanova et al. 2012). At the same time the cut-off points for 
gelotophilia and katagelasticism are much more theoretically defined as no pathological constructs straightly connected to them have been described yet.

The studies of gelotophobia, gelotophilia and katagelasticism confirmed their relevance for Russia. $14.9 \%$ exceeded a cut-off point of 2.5 for gelotophobia in an adult sample (Ivanova et al. 2016b) compared to $7.41 \%$ in a student sample (Stefanenko et al. 2011; Ivanova et al. 2012). Age dynamics were revealed in a socio-demographic study of gelotophobia in Russia $(\mathrm{N}=1,342)$. Gelotophobia changes in strong connection with gender during adolescence and youth, but after 35 years it increases in both men and women, in comparison with the younger ages (Stefanenko et al. 2013). This means that student samples have in general lower gelotophobia than adult samples.

In comparison with the original Swiss study (Ruch \& Proyer 2009), mean gelotophobia was lower and mean katagelasticism was higher in Russia. Moreover, unlike in the original study, gelotophobia and katagelasticism correlated (Ivanova et al. 2016b).

The distribution of gelotophobia in Russia (14.9\%) was close to German data $(11.75 \%)$ (Ruch \& Proyer 2008b), and exceeds gelotophobia in Austria (5.80\%), China (7.31\%) and Switzerland (7.23\%) (Proyer et al. 2012). It is not easy to interpret these differences as far as too many cultural, social, historical and psychological variables are involved, besides the differences in the composition of samples.

Unlike the original study (Ruch \& Proyer 2009), there was no negative correlation between gelotophobia and gelotophilia, but gelotophobia was connected with katagelasticism (Ivanova et al 2016b). 39 per cent were high scorers on gelotophilia, and 29\% - on katagelasticism among the participants with the highest scores on gelotophobia. On the other hand, only $11 \%$ had low level of gelotophobia among those with the highest level of katagelasticism (Ivanova et al. 2016b).

Gelotophilia and katagalesticism positively correlated with both positive and negative humour styles. It is consistent with theoretical understanding: gelotophilia and katagelasticism catch more the direction of laughter rather than its emotional character. Interestingly, gelotophobia negatively correlated with the "positive" humour styles, but was not connected to the "negative" at all. Gelotophilia, having no correlations with indicators of aggression, nonetheless had high correlations with both aggressive and self-defeating humour styles (Ivanova et al. 2016b).

A series of studies on the fear of being laughed at revealed its dependence on the size of locality in terms of average population (Stefanenko et al. 2011, 2013; Ivanova et al. 2012). Gelotophobia was higher in participants from villages, settlements and small towns in comparison with dwellers of bigger towns and cities (Table 3). T-criterion analysis showed mean differences between the groups: between the group 1 and each of the groups 4, 5, 6 $(\mathrm{M} 1=1.99 \mathrm{M} 4=2.09 \mathrm{M} 5=2.12 \mathrm{M} 6=2.20 \mathrm{p}<0.01)$, the group 2 and each of the groups 4, 5, 6 $(\mathrm{M} 2=1.88 \mathrm{M} 4=2.09 \mathrm{M} 5=2.12 \mathrm{M} 6=2.20 \mathrm{p}<0.001)$, and between the group 3 and each of the group 4, 5, $6(\mathrm{M} 3=1.97 \mathrm{M} 4=2.09 \mathrm{M} 5=2.12 \mathrm{M} 6=2.20 \mathrm{p}<0.02)$. Within the smaller localities (groups 1, 2,3) and the big towns (groups 4, 5,6) the differences were nonsignificant. 
Table 3. Mean gelotophobia in localities with different population (Stefanenko et al. 2013)

\begin{tabular}{|l|l|l|l|}
\hline $\begin{array}{l}\text { Group } \\
\text { № }\end{array}$ & Type of locality & $\begin{array}{l}\text { Sample } \\
\text { size }\end{array}$ & $\begin{array}{l}\text { Mean } \\
\text { gelotophobia }\end{array}$ \\
\hline 1 & Megapolices: Moscow, Saint-Petersburg & $\mathrm{N}=387$ & 1.98 \\
\hline 2 & Cities with population over 1,000,000 & $\mathrm{N}=35$ & 1.83 \\
\hline 3 & Towns with population from 100,000 to 1,000,000 & $\mathrm{N}=107$ & 1.97 \\
\hline 4 & Towns with population 50,000 to 100,000 & $\mathrm{N}=330$ & 2.10 \\
\hline 5 & Urban-type settlement, 10,000 to 50,000 & $\mathrm{N}=163$ & 2.12 \\
\hline 6 & Settlements and villages, up to 10,000 & $\mathrm{N}=48$ & 2.2 \\
\hline
\end{tabular}

\section{Discussion}

The series of studies conducted in Russia investigated both motivational aspect of humour (from a joker's point of view) and its perceptional aspect (from a perceiver's point of view). The total data were rather big and heterogeneous, which allowed us to describe national specifics of Russian attitude towards humour and laughter. Its structure is generally defined through a big role of self-directed humour, particularly self-defeating humour style. The most socially adaptive affiliative humour style is closely connected with self-defeating and aggressive styles. Thus "positive" and "negative" humour styles are much less differentiated in Russian humour in comparison with Canada.

According to the methodology of the humour styles investigation, socially adaptive and maladaptive styles are relatively independent. Indeed, in the original Canadian sample the correlations between "positive" and "negative" humour styles were either not found at all or low (Martin et al. 2003). On the contrary, Russian data demonstrated stable and high relation between self-defeating and affiliative humour styles, and in the regional sample - also with self-enhancing style (Ivanova et al. 2014). Also the level of aggressive humour style in Russia was higher in comparison with the original sample, and it was more closely connected to affiliative style, especially in the Moscow sample.

The study of the fear of being laughed at in Russia also revealed some national features. Its distribution in Russia is close to Germany and exceeds gelotophobia in Austria, China and Switzerland. Davies (2009) suggests gelotophobia to be greater in strongly hierarchical societies where shame is one of the main mechanisms of social control. Empirical studies confirmed that gelotophobia profile in general is higher in eastern than western countries (Proyer at al. 2009). Russia is usually taken as a country which combines eastern and western features, but it was always hierarchical in regard with the structure of power.

Russian data also showed higher level of katagelasticism in comparison with the original Swiss study, and its relation to gelotophobia. One third of participants with the highest scores on gelotophobia revealed also the highest levels of katagelasticism, and $40 \%$ gelotophilia. On the other hand only $10 \%$ had low scores on gelotophobia among the high scorers on katagelasticism (Ivanova et al. 2016b). In other words, in Russia people with high gelotophobia may have either high or low levels of gelotophilia and katagelasticism.

The most intriguing is the group of participants who had high levels of gelotophobia and gelotophilia at the same time. These people, having high sensitivity to ridicule, tend to become 
a target of the others' laughter, thus revealing a kind of masochistic tendency. Interestingly, gelotophilia, though having no correlations with any indicator of aggression, had strong connections with both aggressive and self-defeating humour styles. These results are consistent with the relations between self-defeating humour style and the "positive" affiliative and selfenhancing styles, and may demonstrate the role of self-irony in Russia - of either positive or derogatory nature. Thus, in Russia the fear of being laughed at may not necessarily lead to avoidance of laughter and social withdrawal. To the contrary, it may often incite to active exchange of jokes.

A methodological conclusion from these findings is that cross-cultural differences in sense of humour may be described not only as higher or lower expression of concrete variables, but rather in terms of differences in the whole structure of the attitude towards humour and laughter, reflected in different patterns of their interrelations. For example, compared to American data (Ford et al. 2014), in Russia affiliative humour style was lower and aggressive humour style higher. On the other hand, self-defeating humour in USA even exceeded it in Russia.

\subsection{Regional differences}

The Russian study revealed differences in humour styles usage between people from Moscow and residents of other regions of Russia (Ivanova et al. 2014). According to a popular expression, within the country there is Moscow and there is Russia, meaning that Moscow as a capital, an economical centre of Russia differs too much from all the other regions. So, differences in psychological variables could also be expected. And, indeed, they were found.

Interestingly, the correlation between self-enhancing and self-defeating humour styles in the regional sample was relatively high, whereas in the Moscow sample it was not found at all. In other words, the criterion of self-directed humour versus humour directed to others is more crucial in regions than in Moscow where its good/bad nature is more important. The result is consistent to the higher levels of gelotophobia in smaller localities, and may have defencive character: if I laugh at myself I may prevent others' laughter in my address. In big cities there are more possibilities to express oneself in different ways, tolerance to nonconformity is higher, but relative autonomy develops a need of social connections. Thus the role of socially important humour styles increases - both affiliative and aggressive.

In general the data on Muscovites are much closer to the western data than to the regional sample. It may reflect modern cultural convergence characteristic of metropolises. The results of the regional sample are likely to characterise more traditional Russian culture.

Apparently "negative" humour, especially self-defeating humour style, is not perceived in Russia as absolutely negative. This may be explained from cultural-historical point of view.

The studies in different Russian regions revealed inverse relationship between gelotophobia and local population. Some authors suggest that the fear of being laughed at is to be connected with collectivism vs. individualism (Lampert et al. 2010) or interdependence vs. independence in a society (Proyer et al. 2009). The Russian data confirm this view, at the same time contradicting Swiss empirical data where this relationship was not established (Ruch \& Proyer 2009). The contradiction may be explained by the extent of homogeneity of the samples from different areas which is obviously higher in European countries in comparison with Russia.

\subsection{Possible cultural-historical explanations}

An unusual role of self-defeating humour style and potential readiness to be laughed at even in people with expressed fear of laughter may have cultural-historical explanations. National specifics of the attitude towards humour and laughter is reflected in the main character of 
Russian folk-tales Ivan-the-Fool. Despite that (or even for the reason that) he is stupid, lazy, odd, dirty, poor, ridiculous, and never behaves in a proper way, at the end of the story he always gains magic assistants, the princess, and the kingdom. Russian traditions and folklore contain positive and even sacred attitude to weirdness and ridiculousness. A fool, buffoon, trickster appears to be the most wise and lucky (see more on Russian clowns (Popov 1970).

The same way mentally ill people were often perceived as being saint in Ancient Russia (Panchenko 1984). The orthodox culture, prevailing in Russia, stressed the value of martyrdom and self-criticising. It is not accidentally that a phenomenon of "urodstvo" was authentic for Ancient Russia. Coming etiologically from the word "urod" [monster, freak, ugly person], "urodstvo" or "urodiviye Hrista radi" [playing the fool for the sake of Christ] defines a special kind of antisocial behaviour, stupidity, ridiculousness, absurdity, which was at the same time associated with the truth, sacred wise and holiness. "Urodiviye" behaved in a ridiculous way, as mad and stupid, they were laughed at, but at the same time they were expected to say the truth, to be clairvoyants and no one was allowed to hurt them. Russian orthodox church canonised a number of urodiviye as saints (Panchenko 1984; 2000; Ivanov 1994). "Urodiviy" imitates a mentally ill person behaviour for the sake of Christ, it is an extreme form of ascesis, spiritual service based on a negation of rationality (Troitckii 2006). Thus consciously becoming a target of laughter (including aggressive, offencive laughter) is often associated with a struggle with pride in Russia, and is taken as a special value, wise and holiness.

In the Soviet times the value of self-irony and self-laughter was also very high; it was supposed to be an indicator of an intelligent, educated, cultured person. Laughing at one's self (and one's own country, state, society) was an attribute of a true "dissident"- dangerous and respected social status. On the one hand, a joker addressed his jokes to a relatively small circle of close friends. Any stranger could be suspected in betrayal and was indeed potentially dangerous. In the 1930s a person could be prisoned for quite an innocent joke which, in turn, being exaggerated, gave birth to many jokes. On the other hand, a joke was regarded as smart and brave only within this context of high risk. Thereby a very complex, intellectual, polycontextual methaphorical humour was developed in Russia. It had to be oriented to different kinds of audience at the same time, so it had to have several levels of understanding (see more about Soviet culture in Mehnert 1962 and Smith 1991).

Telling jokes escalated into a separate leisure activity in the times of Perestroika, stroke foreigners (Davies 2007). During the Post-Soviet times this phenomenon gradually disappeared. The less dangerous it became to tell political jokes, the less funny they were. But current political and economic changes in Russia are restoring this field, though in virtual discourse it is not as concentrated as it used to be.

Dmitriev \& Sychev (2005) assume laughter to be opposed to fear, and they present historical process as changes from a culture of fear (dictature, rigid ideology) to a culture of laughter (reaction, reassessment of values and norms, searching of new values). A study of socio-cultural features of laughter in a concrete historical period may play a role of a certain social thermometer.

\section{References}

Artemyeva, T.V. (2011). 'O metode issledovaniya sovladaniya (koping) umorom i ego vozmojnostyah' [On the method of coping humour study and its abilities]. Kazan Pedagogical Journal 4, pp.118-123. Available at: http://cyberleninka.ru/article/n/ometode-issledovaniya-sovladaniya-koping-yumorom-i-ego-vozmozhnostyah.

Chafe, W. (2007). The Importance of Not Being Earnest. The Feeling Behind Laughter and Humour. Amsterdam: John Benjamins. 
Davies, C. (2007). 'Humour and protest: Jokes under communism'. International Review of Social History 52, pp. 291-305.

Davies, C. (2009). 'Humour theory and the fear of being laughed at'. Humor: International Journal of Humor Research 22 (1/2), pp. 49-62.

Dmitriev, A.V. \& Sychev, A.A. (2005). Smeh: sociofilosofskii analis [Laughter: Sociophilosophical analysis]. Moscow: Alfa.

Enikolopov, S.N. \& Tsybulsky, N.P. (2007). 'Psikhometricheskii analiz versii oprosnika Bassa-Perri' [Psychometric analysis of Russian version of BussPerry Aggression Questionnaire]. Psychological Journal 1, pp. 115-124.

Ford, T.E., McCreight, K.A., Richardson, K. (2014). 'Affective Style, Humour Styles and Happiness'. Europe's Journal of Psychology 10 (3), pp. 451-463.

Greengross, G. \& Miller, G.F. (2008). 'Dissing oneself versus dissing rivals: Effects of status, personality, and sex on the short-term and long-term attractiveness of self-deprecating and other-deprecating humour'. Evolutionary Psychology 6 (4), pp. 652-666.

Grigorieva, I.V. \& Enikolopov, S.N. (2016). 'Testing questionnaires "Liebowitz Social Anxiety Scale" and "Fear of Negative Evaluation Scale" (short version)'. National Psychological Journal 1, pp. 31-44. Available at: http://npsyj.ru/pdf/npj-no212016/npj_no21_2016_031-044.pdf.

Ivanov, S.A. (1994). Vizanti'skoye urodstvo (Byzantine urodstvo). Moscow: Mejdunarodnye otnosheniya.

Ivanova, E.M., Enikolopov, S.N., Stefanenko, E.A. (2016a). 'Attitude towards humour and laughter in Russia'. Bulletin of the Russian Foundation for Humanities 2 (83), pp. 167181. Available at: http://www.rfh.ru/downloads/vestnik/vestnik_2_16.pdf.

Ivanova, A. M., Mitina, O.V., Stefanenko, E.A., Enikolopov, S.N., Babina, J.N., Zizganova, G.A., Nizovskikh, N.A. (2014). 'Self-defeating humour in Russia and humour styles of muscovites'. Siberian Journal of Psychology 51, pp. 163-175.

Ivanova, A., Stefanenko, E., Enikolopov, S., Proyer, R.T., Ruch, W. (2012). 'The fear of being laughed at in healthy people and psychiatric patients. Assessing gelotophobia in Russia'. Bridging Eastern and Western Psychiatry 8 (1), pp. 10-17.

Ivanova, E. M., Makogon, I.K., Stefanenko, E.A., Enikolopov, S.N., Proyer, R., \& Ruch, W. (2016b) 'Russkojazychnaja adaptazija oprosnika gelotofobii, gelotofilii i katagelasticisma PhoPhiKat' [A Russian-language adaptation of the PhoPhiKat questionnaire on gelotophobia, gelotophilia and katagelasticism]. Voprosy Psychologii, 2, pp. 261-171.

Ivanova, E.M., Mitina, O.V., Zaytseva, A.S., Stefanenko, E.A., Enikolopov, S.N. (2013). 'Russian-language adaptation of the humour styles questionnaire developed by R. Martin'. Theoretical and Experimental Psychology 2, pp. 71-85.

Kirsh, G.A. \& Kuiper, N.A. (2003). 'Positive and negative aspects of sense of humour: Associations with the constructs of individualism and relatedness'. Humor: International Journal of Humor Research 16 (1), pp. 33-62.

Lampert, M.D., Isaacson, K.L., Lyttle, J. (2010). 'Cross-cultural variation in gelotophobia within the United States'. Psychological Test and Assessment Modeling 52 (2), pp. 202 216.

Likhachev, D.S., Panchenko, A.M., Ponyrko N.V. (1984). Smekh v Drevney Rusi. [Laughter in Ancient Russia]. Leningrad: Nauka.

Makogon, I.K. \& Enikolopov, S.N. (2014). 'A technique for measuring inclination to experiencing guilt and shame'. Voprosy Psychologii 4, pp. 118-126.

Martin, R. (2007). The Psychology of Humor: An Integrative Approach. Burlington: Elsevier Academic Press. 
Martin, R.A., Puhlik-Doris, P., Larsen, G., Gray, J., Weir, K. (2003). 'Individual differences in uses of humor and their relation to psychological well-being: Development of the Humor Styles Questionnaire'. Journal of Research in Personality 37, pp. 48-75.

Mehnert, K. (1962). Soviet Man and His World. New York: Frederick A. Praeger..

Panchenko, A.M. (1984). 'Smeh kak zrelische (Laghter as a sight)', in Likhachev, D.S., Panchenko, A.M., \& Ponyrko, N.V. (eds.), Smekh v Drevney Rusi. [Laughter in Ancient Russia]. Leningrad: Nauka.

Panchenko, A.M. (2000). 'Urodivye na Rusi' [Urodivye in Russia], in Panchenko, A.M., $O$ russkoj istorii i kulture [On Russian history and culture]. Sankt Petersburg: Izd-vo Azbuka.

Platt, T. (2008). 'Emotional responses to ridicule and teasing: Should gelotophobes react differently?'. Humor: International Journal of Humor Research 21 (2), pp. 105-128.

Popov, O. (1970). Russian Clown. London: Macdonald \& Co.

Proyer, R.T. et al. (2009). 'Breaking ground in cross-cultural research on the fear of being laughed at (gelotophobia): A multinational study involving 73 countries'. Humor: International Journal of Humor Research 22 (1/2), pp. 253-279.

Proyer, R.T., Ruch, W., Chen, G.-H. (2012). 'Gelotophobia: Life satisfaction and happiness across cultures'. Humor: International Journal of Humor Research 25 (1), pp. 23-40.

Ruch, W. (2009). 'Fearing humour? Gelotophobia: The fear of being laughed at. Introduction and overview'. Humor: International Journal of Humor Research 22 (1/2), pp. 1-25.

Ruch, W., Altfreder, O., Proyer, R.T. (2009). 'How do gelotophobes interpret laughter in ambiguous situations? An experimental validation of the concept'. Humor: International Journal of Humor Research 22 (1/2), pp. 63-90.

Ruch, W. \& Proyer, R.T. (2009). 'Extending the study of gelotophobia: On gelotophiles and katagelasticists'. Humor: International Journal of Humor Research 22 (1/2), pp. 165-182.

Ruch, W. \& Proyer R.T. (2008a). 'The fear of being laughed at: Individual and group differences in gelotophobia'. Humor: International Journal of Humor Research 21 (1), pp. 47-67.

Ruch, W. \& Proyer, R.T. (2008b). 'Who is gelotophobic? Assessment criteria for the fear of being laughed at'. Swiss Journal of Psychology 67 (1), pp. 19-27.

Smith, H. (1991). The New Russians. New York: Random House.

Stefanenko, E.A., Enikolopov, S.N., Ivanova, E.M. (2014). 'The relation to the humour and laugh in patients with schizophrenia'. Zhurnal nevrologii $i$ psikhiatrii imeni S.S. Korsakova 114 (1), pp. 26-29.

Stefanenko, E.A., Ivanova, E.M., Enikolopov, S.N. (2013). 'Sociodemograficheskije aspecty gelotofobii v Rossii' [Socio-demographic aspects of gelotophobia in Russia]. Voprosy Psychologii 2, pp. 104-112.

Stefanenko, E.A., Ivanova, E.M., Enikolopov, S.N., Proyer, R., Ruch, W. (2011). 'Diagnostika strakha vyglyadet' smeshnym: russkoyazychnaya adaptatsiya oprosnika gelotofobii' [Gelotophobia in Russia: the fear of being laughed at diagnostics]. Psychological Journal 1, pp. 94-108.

Titze, M. (2009). 'Gelotophobia: The fear of being laughed at'. Humor: International Journal of Humor Research 22 (1/2), pp. 27-48.

Titze, M. (1996). 'The Pinocchio Complex: Overcoming the fear of laughter'. Humor and Health Journal 5, pp. 1-11.

Troitckii S. (2006) 'Urodiviye i skomorohi kak nositeli <<smehovogo nachala. >>' [Urodivye and skomorokhs as carriers of "laughter spring"]. $\Delta$ ó $\xi \alpha /$ Doxa. Collected Scientific Articles on the Philosophy and the Philology. Vol.9, pp. 18-27. Available at: http://doxa.onu.edu.ua/Doxa9/18-27.pdf.

Yip, J.A. \& Martin, R.A. (2006). 'Sense of humour, emotional intelligence, and social competence'. Journal of Research in Personality 40, pp. 1202-1208.. 